\title{
PLC and SCADA Based Sewage Water Treatment Plant
}

\author{
Anuj Hiray ${ }^{1}$, Omkar Chinchkar ${ }^{2}$, Parth Butte ${ }^{3}$, Mrs. Vaneela Pyla ${ }^{4}$ \\ BE Student, Electrical Engineering Department, N.B.N Sinhgad Technical Institutes Campus, Pune, India ${ }^{1,2,3}$ \\ Assistant Professor, Electrical Engineering Department, N.B.N Sinhgad Technical Institutes Campus, Pune, India ${ }^{4}$
}

\begin{abstract}
Wastewater from homes and industries, without proper treatment, when released into water source can cause harm to aquatic life and disturb the $\mathrm{pH}$ of water causing water pollution. In India, water treatment plants are located across various cities. Proper control and monitoring of these plants can help us improve the productivity thereby limiting scarcity of water as proficient use of water can be achieved. Automation in various separation techniques like bar screening, sedimentation, grit removal, chlorination, Oxidation etc. is being carried out by using programmable logic controller. In this paper, the use of PLC and SCADA in sewage water treatment plant is implemented. The obtained purified water is used for domestic and agricultural purpose on the basis of ph.
\end{abstract}

Keywords: Automation, Programmable Logic Controller (PLC), Supervisory Control and Data Acquisition (SCADA), Water treatment, Potential of hydrogen $(\mathrm{pH})$.

\section{INTRODUCTION}

Water is the most important natural resource available to mankind. Around $71 \%$ of Earth's surface is covered by water out of which only $2.5 \%$ is suitable for consumption by humans. Out of this, $1.7 \%$ in groundwater, $1.7 \%$ in glaciers at Antarctica and Greenland, $0.001 \%$ in air as vapour, cloud and precipitates. ${ }^{[1]}$ Drought in India has resulted in tens of millions of deaths over the course of $18^{\text {th }}, 19^{\text {th }}$ and $20^{\text {th }}$ centuries. Indian agriculture is heavily dependent on climatic conditions. A water scarcity problem arises due to inadequate water treatment facilities, rapid growth in human population, and lack of investments in treatment plants. Wherever facilities are available, they are not maintained properly.

\subsection{Problem Statement:}

- To make use of polluted and sewage water for agriculture and domestic purpose after treatment.

- Monitoring and control of water treatment using PLC and SCADA operations.

\subsection{Objective:}

Avoid wastage of water by recycling water discharged from homes, businesses, and industries and reduce water pollution, for use in agricultural sector and domestic purpose.

\subsection{Need of automation:}

Present economic and environment concerns require businesses to take a realistic approach towards productivity, improvement in quality of product, reducing operating time and cost. The goal is to make full utilization of assets such as raw material, system, labour etc. Automation is a standout method to accomplish this. Automation can be characterized as the use of logical methods to automate the operation as well as control of hardware, processes, or system, with an objective to limit human interruption and accomplish the above. Automation has monetary effects as cost included and all the more imperatively as reserve funds.

Some of the benefits of automation can be summarized as:

- Enhanced item quality

- Increase in Reliability

- Eco-friendly operation

- Increase in profitability

- Decrease in downtime, maintenance and operation costs

- Utilization of labour in other sectors where automation is not feasible

- Accurate data/information can be obtained, real time operation and better process control

- More noteworthy consumer loyalty and brand use 


\section{ISO 3297:2007 Certified}

Vol. 5, Issue 5, May 2017

\section{$1.4 \mathrm{pH}$ table for various applications:}

Table 1: pH Range of agricultural crops ${ }^{[8]}$

\begin{tabular}{|c|c|c|}
\hline Sr. No. & Application & $\mathrm{pH}$ Range \\
\hline 1 & Potato & $4.8-6.5$ \\
\hline 2 & Sweet potato & $5.2-6$ \\
\hline 3 & Tomato & $5.5-7.5$ \\
\hline 4 & Eggplant & $5.5-6.5$ \\
\hline 5 & Cabbage & $6-7.5$ \\
\hline 6 & Grapes & $5.5-7.0$ \\
\hline 7 & Blueberry & $4.5-5.5$ \\
\hline
\end{tabular}

Table 2: pH Range of domestic plants ${ }^{[8]}$

\begin{tabular}{|c|c|c|}
\hline Sr. No. & Application & pH Range \\
\hline 1 & Blue Grass & $6.5-7.5$ \\
\hline 2 & Oak(Black) & $6-7$ \\
\hline 3 & Oak(White) & $5-6.5$ \\
\hline 4 & Rose, hybrid tea & $5.5-7.0$ \\
\hline 5 & Beautybush & $6.0-7.5$ \\
\hline
\end{tabular}

\section{TREATMENT TECHNIQUES}

2.1 Screening: As per figure 4, reservoir tank is the source of sewage. So tank 1 contains wastewater. Tank 1 is provided with grit chamber and filter assembly to remove large objects such as stones, plastic etc. After some time delay, a pipe transfers the sewage water from tank 1 to tank 2 . Here we are using iron net which is use to eliminate small solid particles, plastic, covers etc. from sewage water. In this process water is allow to stay for some time.

2.2 Sedimentation: As soon as sufficient water from tank 1 is taken in the tank 2, pipe closes. Here stirrer is used which operates on motor. This stirrer is moving very slowly at the top of the water in order to collect all the floating solids which is not removed in screening process. Here it slows down and the suspended solids gradually sink to the bottom. This mass of solids is called primary sludge. Various methods have been devised to remove primary sludge from the tanks. As water remains in the tank for some time sludge settle down at the bottom of the tank. After a certain time delay pump 1 turns on and chlorine water goes into Tank 2.

2.3 Chlorination: Water in tank 2 is kept stable until chlorination is completed. In tank 2, it is treated with alum and chlorine water. As in fig. 4 there are two small tanks above the tank 2 which contains alum and chlorine. They are controlled by pump 1 . According to the value of $\mathrm{pH}$ of the water, particular amount of alum and chlorine is added into tank. Alum helps to settle the sludge at bottom so water gets clean and chlorine is used as purifying agent which kills the bacteria in the water. As soon as alum and chlorine are added, stirrer in tank starts rotating. Stirrer is used in order to mix the mixture properly. Once the pump 2 is opened, Stirrer stops rotating. After certain amount of delay pump 2 is opened and water from tank 2 is transfer into tank 3 . As water moves, sludge into tank 3 is removed by the manually operated tank. Tank 3 is also provided with limit switches which controls the limit of the tank.

2.4 Oxidation: Tank 3 contains an AC pump operated with the help of relays to increase the amount of oxygen in the tank as the oxidizing properties can also reduce the concentration of iron, manganese, sulphur and reduce or eliminate taste and odour problems. The raw water is then passed through a suction pump which creates a vacuum and pulls the ozone gas into the water or the air is then bubbled up through the water being treated. Sample of water is taken from tank 3 to measure the $\mathrm{pH}$ of water. Once the $\mathrm{pH}$ is considered suitable, Solenoid valve SV1 and SV2 are opened according to the purpose.

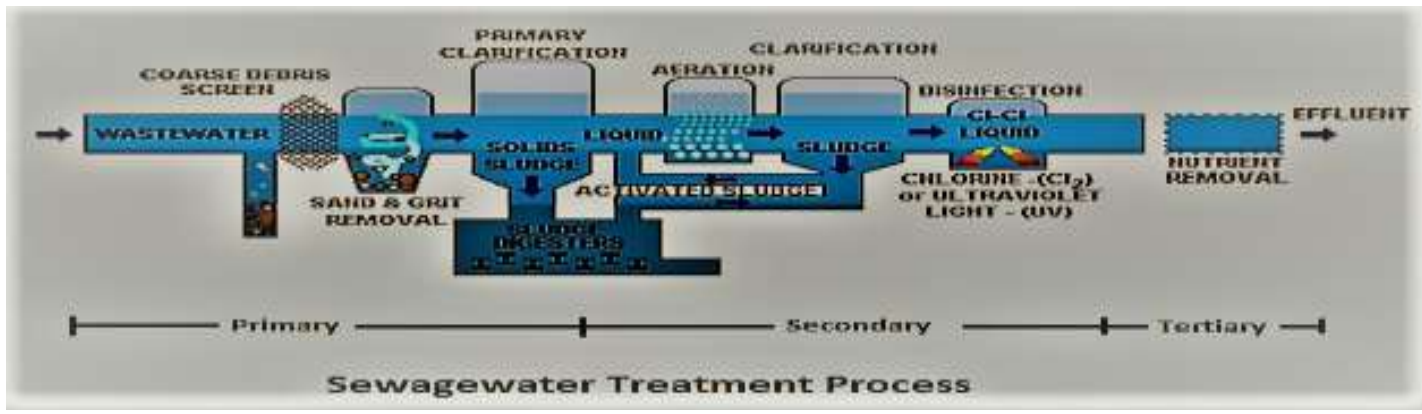

Fig 1. Typical Sewage Water Treatment Process 


\section{EQUIPMENT SPECIFICATION}

A PLC consists of CPU, memory, input/output ports, relays, timers, counters and data storage containers. Modular plc of s7-300 is used for low end and mid-range performance. It has 312 to 318 modules and has 1024 digital input/outputs ports and 38 analog input/output ports. Out of these, the project requires 8 DO ports for operation of 3 DC pumps, 1 AC pump, 1 motor and 2 solenoids. Simatic manager is used as programming software for PLC. Simatic winCC software is used for SCADA programming.

Languages in PLC:

1. Ladder Diagram

2. Functional Block Diagram

3. Structural text

4. Instruction List

5. Sequential functional charts

From the above methods, ladder diagram is used. The essential prerequisite for a successful water industry: first-class process quality. The perfect conditions for this are provided by Totally Integrated Automation - for example with the SIMATIC S7 process control system. This innovative process control system controls all processes throughout the plant and provides the basis for effective and safe process management. Widely distributed or remote plants such as pumping stations can be controlled and monitored extremely efficiently.

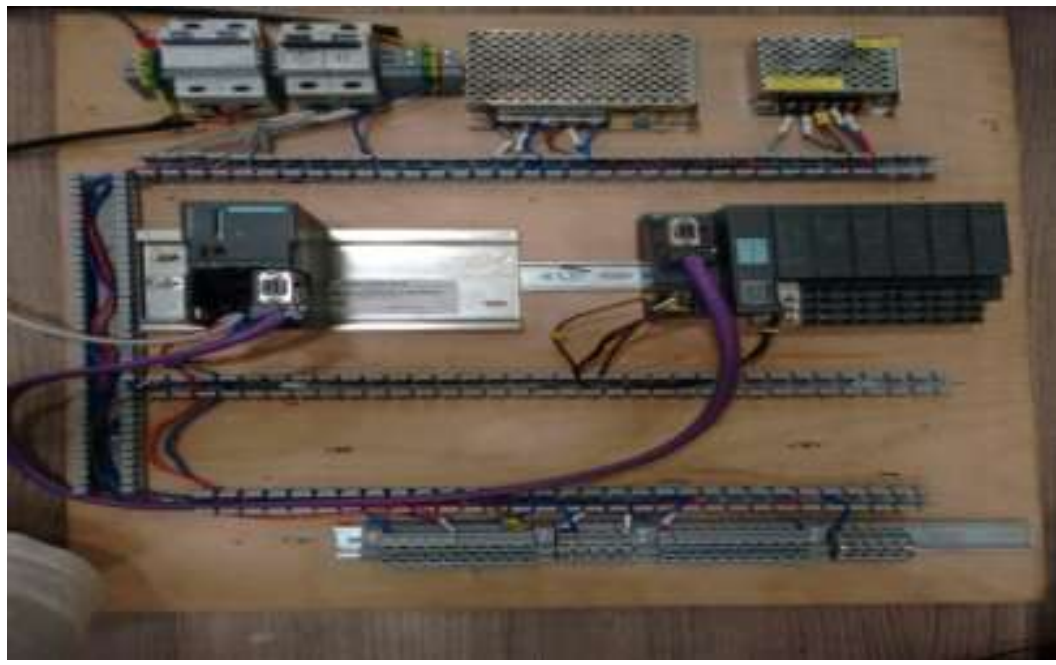

Fig 2. PLC Circuit

\section{BLOCK DIAGRAM}

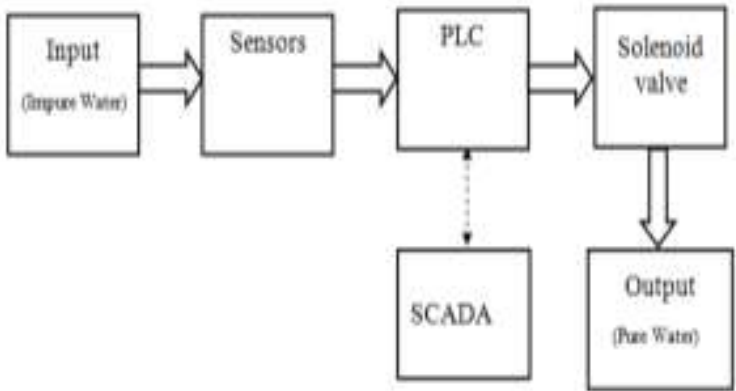

Fig 3. Block Diagram

\section{RESULTS}

\subsection{SCADA Screen}

The SCADA screen as (Fig. 4) monitors and controls the overall process of sewage water treatment. With the help of this screen operator can give signals to all the ongoing field operations. One emergency stop key is provided on the 
screen which can be used in emergency situation. When operator receives $\mathrm{pH}$ data he puts $\mathrm{pH}$ value on screen and depending upon the $\mathrm{pH}$ value purified water will be distributed to either domestic or agricultural use.

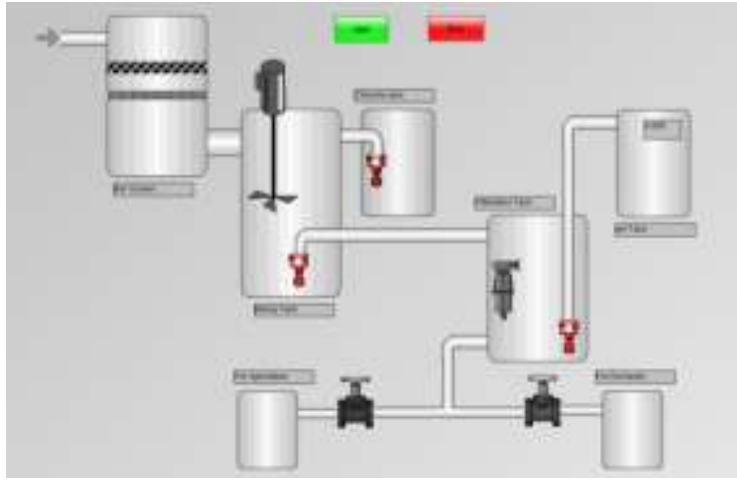

Fig 4. SCADA Screen

\section{ADVANTAGES AND LIMITATIONS}

\subsection{Advantages:}

1. Maximize energy savings through integrated, real-time process and equipment information and coordinated, enterprise-wide energy management programs

2. Achieve higher productivity, reduced operating costs, and better utilization of staff with advanced process automation, communication, and information management

3. Reduce potential environmental problems such as overflow, with early detection of failures and weather warnings.

4. Track and control manpower costs through a centralized monitoring and control system that reduces the amount of time and energy that personnel must spend on auxiliary equipment operation and maintenance

\subsection{Limitations:}

1. Fail-safe operation. Does not start automatically when power failure (can be programmed into) not "Fail-safe" -Failshorted rather than OPEN

2. Although Cost of PLC is one time investment it can be a problem because of weak financial support

3. Multiprogramming is not possible in PLC as it is capable of holding one program at a time

4. Skilled labour workforce is required to operate the newly designed automated system

\section{CONCLUSION}

This paper has been done using a process control and monitoring of a Sewage water treatment plant. It has been initiated to implement an expert system in the total control of the process and has been complemented. This has revealed in real time the operation state of the process, which allows us to monitor the process, rectify the errors if any. The decision of a PLC as a control instrument helps us in transferring the control signals to various field devices, it increases compatibility of various equipments through interfaces and protocols, also makes the interoperability with the SCADA implementation.

\section{REFERENCES}

[1] Sravanthi Animireddy, M.P Sharma, "AUTOMATION OF COMMON EFFLUENT TREATMENT PLANT" International Journal of Advanced Technology in Engineering and Science www.ijates.com Volume No.03, Issue No. 02, February 2015

[2] Emerson Process Management, "Plant Automation and SCADA Solutions for the Water \& Wastewater Industries"

[3] Honeywell Process Solutions, "Increasing the Value of Automation for Municipal and Industrial Wastewater Projects"

[4] G.Venkateswarlu, Jayashree Sahu, Y.Sriya, Sruti Pappala, "PLC and SCADA Based Secured and Sustainable Living" -International Journal of Advanced Research in Electrical, Electronics and Instrumentation Engineering (An ISO 3297: 2007 Certified Organization) Vol. 4, Issue 4, April 2015

[5] Corina Maria DINIŞ, Gabriel Nicolae POPA, "Measurements in SCADA systems used at a waste water treatment plant" (Faculty of Engineering, University Polytehnica Romania)Tome XII [2014] -Fascicule 4 [November] ISSN: 1584- 2673

[6] J. Bouza-Fernandez, G. Gonzalez-Filgueira, S. de las Heras Jimenez, D.Vazquez-Gonzalez, "Expert System of a Sewage Treatment Plant for Wood Industry" (IEEE, 2010)

[7] www.allaboutcircuits.com

[8] http://pss.uvm.edu/ppp/pubs/oh34.htm

[9] www.electrical-engineering-portal.com 